James Madison University JMU Scholarly Commons

Department of Mathematics and Statistics - Faculty

Scholarship

Department of Mathematics and Statistics

2015

\title{
Architectural Acoustical Oddities
}

Zev C. Woodstock

Caroline P. Lubert

James Madison University, lubertcp@jmu.edu

Follow this and additional works at: http://commons.lib.jmu.edu/mathstat

Part of the Architectural Engineering Commons, and the Mathematics Commons

\section{Recommended Citation}

Woodstock, Z. C., \& Lubert, C. P. (2014, October). Architectural acoustical oddities. In Proceedings of Meetings on Acoustics 168ASA (Vol. 22, No. 1, p. 025002). ASA. https://doi.org/10.1121/2.0000038

This Article is brought to you for free and open access by the Department of Mathematics and Statistics at JMU Scholarly Commons. It has been accepted for inclusion in Department of Mathematics and Statistics - Faculty Scholarship by an authorized administrator of JMU Scholarly Commons.

For more information, please contactdc_admin@jmu.edu. 


\section{(s). Proceedings of Meetings on Acoustics}

Volume 22

http://acousticalsociety.org/

\section{8th Meeting of the Acoustical Society of America}

Indianapolis, Indiana

27-31 October 2014

\section{Education: Paper 2aED5}

\section{Architectural acoustical oddities}

\section{Zev C. Woodstock}

Department of Mathematics and Statistics, James Madison University, Harrisonburg,

VA; woodstzc@dukes.jmu.edu

\section{Caroline P. Lubert}

Department of Mathematics and Statistics, James Madison University, Harrisonburg, VA; lubertcp@jmu.edu

This paper offers a review of two types of acoustic oddity caused by periodic architecture. These periodic structures of interest are brick plazas and staircases with special dimensions. When an observer stands by one of these periodic structures and produces a percussive white noise, a high-pitched sound can be heard. The frequency of the returned sound is unrelated to the initial sound, and completely determined by the architecture of the structures themselves. This phenomenon is called repetition pitch. Comparative work done at James Madison University is offered to show the relationship between brick plazas at JMU and the repetition pitch effect. 


\section{INTRODUCTION}

This study discusses two general types of acoustic oddities, the phenomenon causing the effects, and offers qualitative evidence relating the acoustic effect to the proposed phenomenon. The first acoustic oddity occurs when sound is reflected from staircases. Two examples of these acoustically interesting staircases are El Castillo Pyramid in Chichen Itza, Mexico and Chantilly Castle in Chantilly, France. In both cases, when one stands in front of the staircase and claps, they hear a reflected sound; however, the reflection resembles the chirp of a bird more than a clap. The other form of acoustic oddity concerns circular brick plazas. This happens in a multitude of locations including James Madison University's campus and Ursinus College's campus. In each location, there is a circular brick plaza on the ground outdoors. When one stands on the circle and claps, a high-pitched squeak sound is audible. Even more interesting is the fact that on some of these circular surfaces the apparent 'squeak' is only audible if one is very close to the center of the circle. Both types of oddity are produced by a similar phenomenon, called repetition pitch (Bilsen "Huygens"; Dimidio).

\section{REPETITION PITCH IN PERIODIC STAIRCASES}

Repetition pitch occurs when an initial percussive white noise (e.g. a clap, snap, or stomp) is reflected from a periodic structure. In the case of these staircases, the observer claps and the sound is reflected from each successive stair. Since each subsequent reflection has a larger distance to travel, these reflections return to the observer at different times. The human ear then interprets these small pulses as a sound's frequency. Thus, repetition pitch can make one hear pitches that have virtually nothing to do with the initial frequency of the sound made by the observer! Perhaps the most wellknown phenomena surrounding acoustically odd staircases are those at El Castillo Pyramid and the stone staircase outside Chantilly Castle.

\section{$\underline{\text { 2.1 El Castillo Pyramid }}$}

The El Castillo Pyramid is located in Chichen Itza, a Maya ruin on the Yucatan Peninsula. When one claps in front of the pyramid's main staircase, the sound reflected back resembles the call of a Quetzal Bird, a significant bird in Maya lore. In 1998 David Lubman, a member of the Acoustical Society of America, went to the site and collected sound recordings, dimension measurements of the pyramid, and pictures. In his article, "An Archaeological Study of Chirped Echo from the Mayan Pyramid of Kukulkan at Chichen Itza", he notes how the auditory reflection both has a definable pitch and lasts longer than a clap. In a mathematical analysis of the data he recorded, Lubman suggested that the initial reflected frequency depends on the tread length of the stairs. He also noticed that the lowest perceptible frequency depends on one's distance from the base of El Castillo. Lubman hypothesized that this lowest frequency depends upon the hypotenuse between the staircase treads and the riser height (visible in Figure 1). 


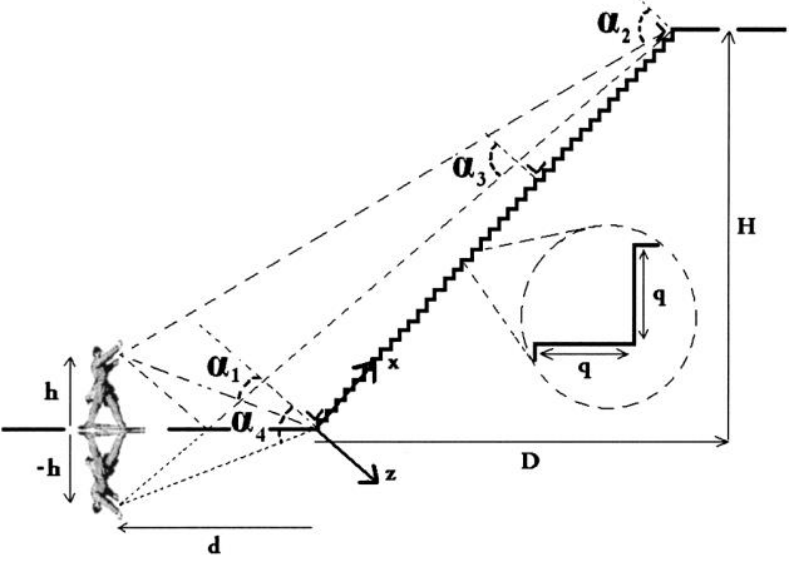

Figure 1: Diagram

of the pyramid's

corrugated

staircase with an

observer in front.

Frans Bilsen, one of the first physicists who studied repetition pitch, obtained Lubman's data and released his analysis in 2006. In the case of El Castillo Pyramid, the vertical face of each step provides a reflective surface for the white noise produced by an observer, resulting in repetition pitch. Bilsen claimed the resulting pitch is a cosinusoidal function with varying frequencies. These frequencies vary in multiples of a 'fundamental' frequency, which corresponds to the reciprocal of the delay time. Repetition pitch theory relates the resultant pitch to the delay time and, therefore, distance from the source. Because distance traveled by the reflected wave dictates the pitch, it appears that Lubman's original prediction was not very far off. Lubman had predicted there was a relation between a staircase's hypotenuse and the reflected pitch, which Bilsen's theory also supports. One interesting part of this phenomenon is that the predicted 'fundamental' frequency doesn't appear in the reflected sound. In fact, the $3^{\text {rd }}$ and $4^{\text {th }}$ harmonics are the most perceptible frequencies, as seen in Figure 2 (Bilsen "Repetition...Glide"). Perhaps the higher frequencies are more audible due to the structural properties of the limestone at Chichen Itza.

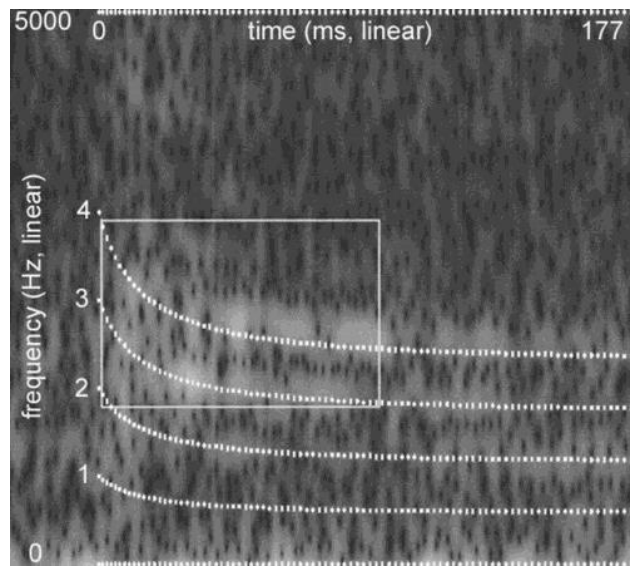

Figure 2: Spectral analysis of the reflected 'chirp' sound produced by Declercq et al. based on data collected by Lubman. White areas indicate the intensity of each frequency. Dotted lines 1 through 4 respectively represent the expected harmonic frequencies based on Bilsen's model. Notice how pitch 'glides' down with time.

\section{$\underline{\text { 2.2 Staircase at the Castle of Chantilly de la Cour }}$}

When one claps in front of the large stone staircase in the garden outside of Chantilly Castle, a similar chirping sound can be heard. Christiaan Huygens first recorded this in 1693 (Huygens). Based on a translation of his account, it appears that the designers of the staircase did not intend for this acoustic effect to happen (Bilsen 
"Repetition Pitch"). Huygens was the first to document and experiment on this chirping phenomenon. Huygens originally hypothesized that the sound came from the combination of the staircase's reflection and a fountain directly behind the staircase. He believed white noise from the fountain might have had a causal effect. He tested his hypothesis by returning in the winter when the staircase was covered in snow and the fountain was still running. Huygens noticed that the sound disappeared, so concluded that the staircase played a significant role in the creation of the sound (Bilsen "Huygens").

This staircase exhibits repetition pitch geometry as well. It is worth noting that, unlike El Castillo, the tread length of the stairs exceeds the increase in height (i.e. small slope). This shows that this acoustic phenomenon is not unique to a particular type of staircase; this phenomenon can be brought about in a multitude of ways from drastically different staircases. Perhaps the size and periodicity is the common denominator between the two staircases. It seems plausible that in order for repetition pitch to be audible, there must be a sufficient number of reflections. Similarly to El Castillo, both stairs provide many reflective surfaces for the repetition pitch squeak to be perceptible.

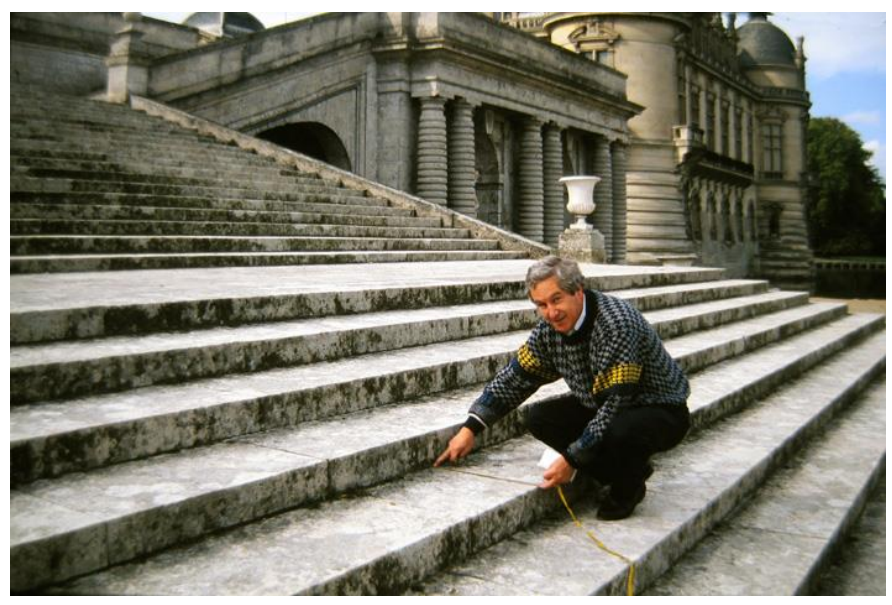

Figure 3: Frans Bilsen measuring the dimensions of the staircase in Chantilly Gardens. Note the stairs have drastically different dimensions than that of $E l$ Castillo.

\section{REPETITION PITCH IN BRICK PLAZAS}

When the observer stands on an acoustically odd brick plaza and makes a percussive white noise, repetition pitch causes a high frequency squeak to occur. All of the plazas that produce this effect have a periodic structure, in that their brick layout follows a repeating pattern. As the sound created by the observer propagates out, it reflects from the small indentations between the bricks. Remarkably, these bevels have enough surface area at an angle capable of sending a reflection back to the observer. The combination of these reflections from each brick bevel results in the 'squeak' (DiMidio).

Bilsen's repetition pitch theory is the best explanation for this phenomenon. Repetition pitch occurs when an incident sound and its reflection(s) occur in a very close time period. When the incident sound and its reflections recombine, the air in the area oscillates very quickly. This rapid oscillation of air causes the observer to hear a higher pitch. This does not necessarily mean that there is a change in frequency of the incident sound or its reflection; rather, the frequency at which the reflections reach the observer causes the repetition pitch effect. One requirement for this effect is that the reflection's 
delay time is short; without this prerequisite the observer will simply hear the incident sound followed by its echo (Bilsen "Repetition...glide"). This is why one can rule out the possibility of the squeaking phenomenon being caused by reflections from adjacent building: the squeak occurs too quickly for the sound to have traveled a distance greater than the brick circle (DiMidio). Repetition pitch is most prominent when the incident sound is caused by a white noise. Because all frequencies are on a similar level, there is no specific tone that can overpower the effect caused by repetition pitch (Bilsen "Huygens"). When one claps on a plaza with no bevels, no sound is produced. Similarly to Huygens' experiment hundreds of years ago, this can easily be tested by clapping on one of the plazas after it has snowed. It follows that the source of these reflections must be related to the grooves between the bricks.

\section{$\underline{\text { 3.1 Ursinus College (Philadelphia, Pennsylvania) }}$}

There are three locations on Ursinus' campus where acoustic anomalies occurs. Each location is a flat, circular brick formation; however, the lay of their brick and the diameter of the circles vary. If one stands on of any one of these circles and claps (or makes any percussive white noise) then a 'squeak' sound is produced. In one of the circles the squeak is only audible in the center; as one travels radially from the center, the squeaking phenomenon dissipates. However, the sound is equally audible anywhere on the other two circles. It is believed that the variation in brick pattern causes this difference in the association of location and repetition pitch intensity (DiMidio).

\subsubsection{The Labyrinth}

The location where the squeak sound is most easily audible is known as "The Labyrinth." This location has a brick pattern that consists of concentric circles, depicted in Figure 4. The interesting thing about this plaza is that the squeaking phenomenon is only audible when one stands close to the center of the circle. Perhaps because many of the grooves face the center of the circle, they act to reflect the incident sound back at the observer standing in the center.

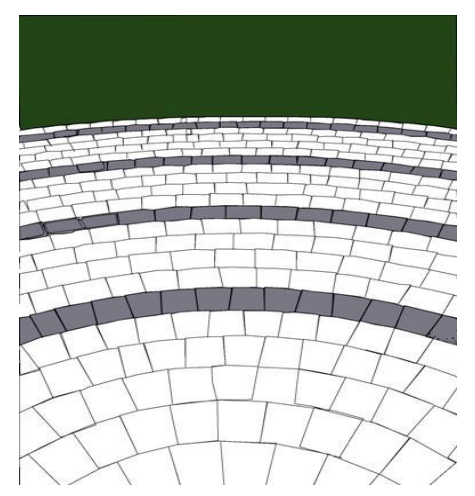

Figure 4: The pattern at the Labyrinth in Ursinus College has a concentric circular brick pattern. Notice how a significant portion of the grooves face directly at the center of the circle. 


\title{
3.1.2 The 1952 and Rimert Plazas
}

Two other locations on Ursinus' campus also produce this interesting squeaking sound. The first is the Class of 1952 Circle, which has a much larger diameter than the Labyrinth. The second is the Rimert Circle, located just outside of the Rimert Residence Hall. The squeaking phenomenon is more or less equally audible anywhere on either circle (as opposed to only being audible in the center of the circle). Their brick pattern and diameter also differ from the Labyrinth. Instead of a concentric circular brick pattern, both of these circles have rectilinear patterns, as displayed in Figure 5 (DiMidio).

\author{
Figure 5: The rectilinear \\ brick pattern exhibited in the \\ 1952 Circle and the Rimert \\ Circle. Notice how these \\ grooves do not face the \\ center. This is believed to be \\ why the squeaking \\ phenomenon is equally \\ audible anywhere on the \\ circles.
}

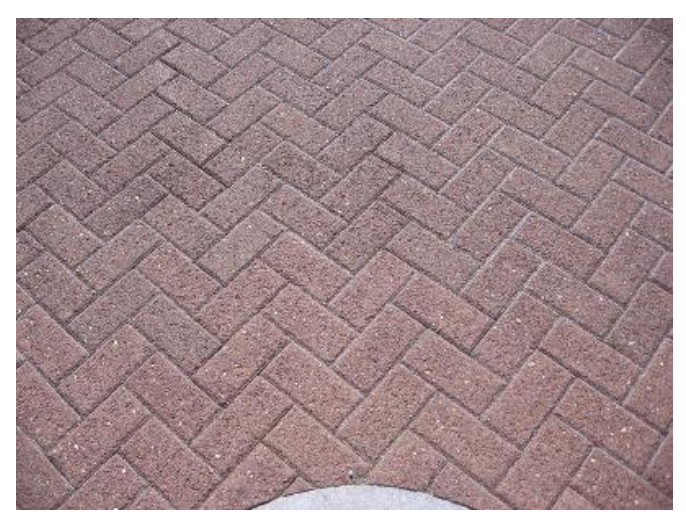

Because all of the grooves between the bricks do not face the center of the circle, it follows that the squeak phenomenon would not be focused at the center. However, this does not explain why repetition pitch allows the squeak phenomenon to occur anywhere on the circle. This must be because, at any point on the circle where repetition pitch is audible, there are enough brick grooves at the correct angle to reflect the incident wave such that the squeak effect is strong enough to be audible. Because repetition pitch requires a high number of reflections, it makes sense that one would need a larger rectilinear surface in order to produce the same amount of reflection (and thereby sound) as a concentric circular surface. In fact, that is the case: The 1952 circle (rectilinear pattern \& large size) and the labyrinth (concentric circular pattern \& medium size) have approximately the same level of repetition pitch audibility, while the Rimert circle (rectilinear pattern \& medium size) is the hardest to get to produce the squeak effect (DiMidio).

\subsubsection{Mathematical frequency derivation of repetition pitch}

An experiment conducted by Dante DiMidio, a physicist at Ursinus college, exemplified the relationship between path distance and frequency extremely well. If one considers the path length of the $\mathrm{n}^{\text {th }}$ reflected wave then the total distance that each reflected wave travels $s(n)$ is given by,

$$
s(n)=\sqrt{Z_{0}^{2}+r_{n}^{2}}+\sqrt{\left(Z^{\prime}+Z_{0}\right)^{2}+r_{n}^{2}}
$$


where $r_{n}$ is the radius from the center of the circle to the $\mathrm{n}^{\text {th }}$ bevel, $Z_{0}$ is the distance from the ground to the clap, and $Z^{\prime}$ is the distance from the clap to the microphone. The variables are displayed graphically in Figure 6.

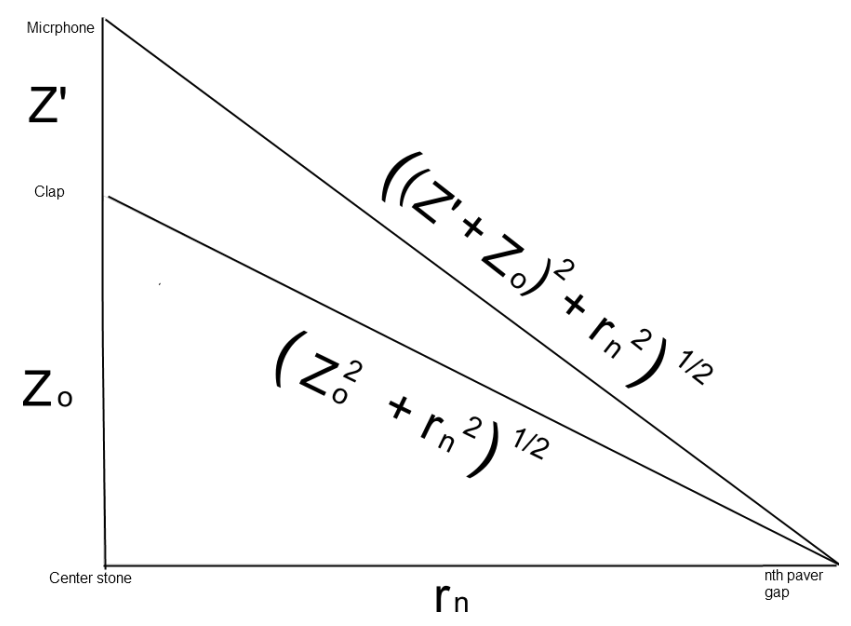

Figure 6:Graph depicting path of a reflected sound wave

One can solve for the travel time $T(n)$ using $s(n)$ and $V_{s}$, the speed of sound at current temperature and pressure:

$$
\tau(n)=\frac{s(n)}{V_{s}}
$$

So the time delay between subsequent reflections $\Delta T$ is given by,

$$
\Delta T=\tau(n+1)-\tau(n)
$$

Finally, the frequency at which the reflected pulses reach the observer (and the frequency of the apparent repetition pitch sound effect) is related to the inverse of the delay time,

$$
f_{m}(n)=\frac{m}{\Delta T}, \quad m=1,2, \ldots m \text { and } n=0,1,2, \ldots 41
$$

where $n$ is the bevel number and $m$ is each harmonic frequency ( $m=1$ being the fundamental frequency) of the tone (DiMidio). The bevel number $\mathrm{n}$ ranges from 0 to 41 , because there were 41 concentric brick circles in this study. The cumulative effect of these frequencies results in a pitch "glide," seen experimentally in Figure 2. It should be noted that this frequency derivation also holds for the staircases, the only difference being how to solve for the path length of each reflection, $s(n)$.

This model implies that as the path length increases, the frequency will asymptotically decline. Because repetition pitch frequency has this declining characteristic, it can be called a 'discrete' form of the Doppler effect. As a train or car approaches an observer, the Doppler effect describes that the sound's frequency slowly increases due to the velocity of the noise being generated. The noise is reaching the observer faster than it would normally, resulting in a higher frequency. This is analogous to when the first few reflections from a stair or brick bevel reach the observer. The time 
differential between the first few reflections is much smaller than that between the last reflections, resulting in an apparent 'glide' from a high frequency to low.

\subsection{James Madison University (Harrisonburg, Virginia)}

Similarly to Ursinus, JMU has several locations on campus where the same squeaking phenomenon occurs. Just like the Labyrinth at Ursinus, if one stands in the center of any of these circles and makes a percussive white noise, a 'squeak' sound results. All of these circles have a concentric circular brick pattern, the same mechanism believed to cause the squeaking sound in the Labyrinth (Figure 4). An example of the brick lay from James Madison's campus is shown in Figure 7.

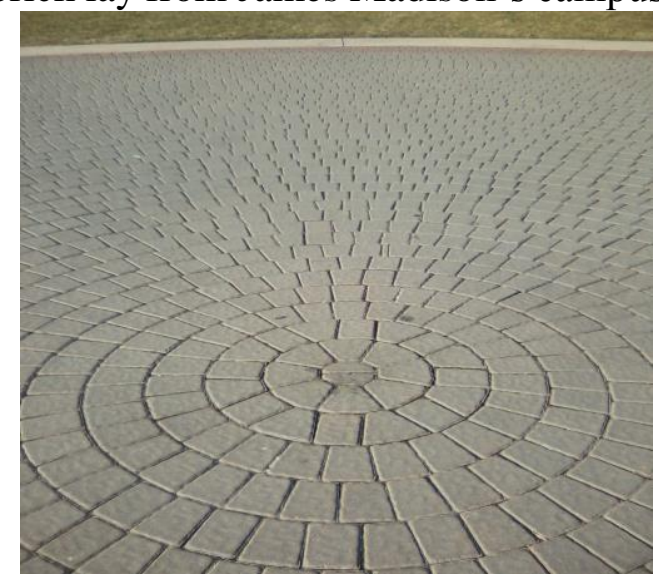

Figure 7: An example of the

brick pattern on James Madison

University's quad

Each of the plazas on JMU's campus produce a very similar repetition pitch squeak effect because their diameters are similar and they have identical distances between successive bevels.

Preliminary experiments have shown that the relation Huygens noted between repetition pitch and snow coverage holds true for the circles on JMU's campus. Recordings were taken in the center of the quad circle the day after a snow. Unfortunately part of the circle had been partially plowed; however, the other half of the circle was still covered in snow. However, this experiment still produced data that comparatively supports the relationship between repetition pitch and the brick bevels. If one compares recordings of a clap at both the plaza covered in snow and the same plaza on a sunny day, the repetition pitch "glide" is definitely visible in a spectral analysis program (Figure 8). While the differences in a spectral analysis photo are hard to see, auditory differences were definitely detected between recordings, displaying a noticeable difference when the brick bevels were filled with snow. 


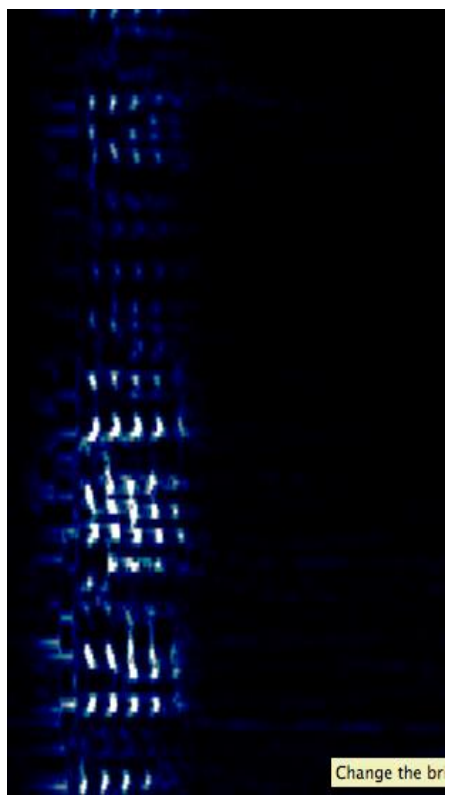

(a)

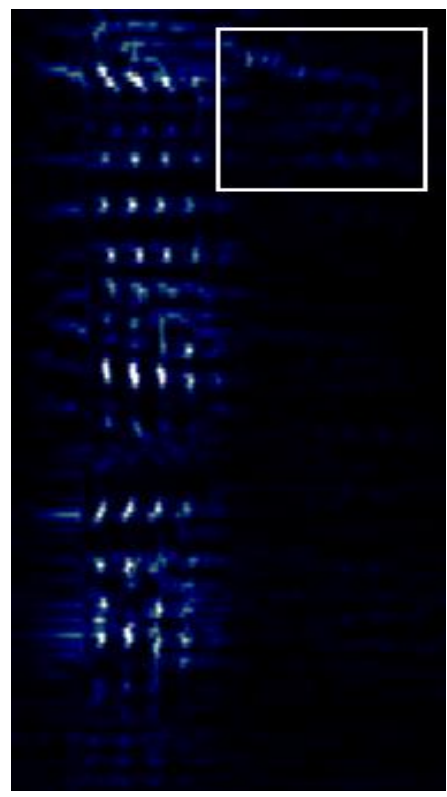

Figure 8. (a) Spectral analysis of a clap at the center of a Brick Plaza covered in snow

(b) Spectral analysis of a clap at the center of a Brick Plaza cleared of snow. Notice that the boxed region has an area of downwardgliding frequency

(b)

\section{RESULTS \& CONCLUSIONS}

Through research in these acoustic phenomena, one can gain a better understanding of repetition pitch. These phenomena are caused by the recombination of an incident sound and its reflections. Each reflection frequency is related to the reflected wave's delay time (and unrelated to the frequency of the initial sound). The cumulative effect of these reflections results in a new pitch that sounds completely different from the original sound. Repetition pitch can be brought about in several ways, and we are still only beginning to understand how it works. If this phenomenon can be manipulated, perhaps one day we will be able to engineer structures to produce significant sounds as the Maya did with the Quetzal bird's call.

If given time to conduct further work on this subject, the author would conduct a more controlled coverage experiment on the circular structures. Now that the preliminary experiment qualitatively supports the relationship between repetition pitch and brick bevels, there are several more pressing questions such as "does the resultant pitch change when the brick length changes?" and "what other structures could produce this effect?" 


\section{REFERENCES}

Bilsen, Frans A. "Huygens on Pitch Perception; Staircase Reflections Reconsidered." Nederlands Akoestisch Genootschap 178 (2006): 1-8. Web. 14 nov 2013

Bilsen, Frans A. "Repetition Pitch." Frans A. Bilsen's Homepage. Frans A. Bilsen, n.d. Web. 9 Sept. 2013.

Bilsen, Frans A. "Repetition Pitch Glide from the Step Pyramid at Chichen Itza." Journal of The Acoustic Society of America 120.2 (2006): 594-96. Print.

Declercq, N. F., R. Briers, O. Leroy, and J. Degrieck. "A Theoretical Study of Special Acoustic Effects Caused by the Staircase of the EI Castillo Pyramid at the Maya Ruins of ChichenItza in Mexico." Journal of the Acoustical Society of America 116.6 (2004): 3328-335. Print.

DiMidio, Dante. "Acoustic Anomalies in Brick Paver Circles at Ursinus College." UrsinusWiki. Ursinus College, 2010. Web. 9 Sept. 2013.

Huygens, C. (1693). "En envoiant le problème d'Alhazen en France," Correspondance No. 2840 printed in Oeuvres Complètes, Vol. 10, ed. Societé Hollandaise des Sciences (Nijhoff, Den Haag, 1950), pp. 570-571.

Lubman, David. "An Archaeological Study of Chirped Echo from the Mayan Pyramid of Kukulkan at Chichen Itza." Acoustical Society of America. Orange County Regional Chapter of the Acoustical Society of America, 1 Feb. 1999. Web. 9 Sept. 2013. 